\title{
Minors' access to tobacco before and after the California STAKE Act
}

\author{
Hope Landrine, Elizabeth A Klonoff, Astrid Reina-Patton
}

\begin{abstract}
Objective-To assess the effect of implementation and enforcement of the California STAKE Act on minors' access to tobacco by examining sales over time in the same stores.

Design-Sixteen year old girls and boys attempted to purchase cigarettes in the same 72 stores, in the same manner, in five time periods: August 1994 (before implementation of legislation); August 1995 (immediately after implementation); August 1996; March 1998; and January 1999 (all postimplementation).

Outcome measure-Percentage of successful cigarette purchases over time, in different ethnic communities.

Results-Minors' access rate decreased significantly from $41.2 \%$ before implementation of legislation (1994) to $12.7 \%$ after implementation (1998). The same stores were 3-5 times more likely to sell cigarettes to minors before than after the legislation was implemented, irrespective of ethnic census tract.

Conclusions-The California STAKE Act and its enforcement have been effective in reducing minors' access to tobacco in all ethnic communities.

(Tobacco Control 2000;9(Suppl II):ii15-ii17)
\end{abstract}

Keywords: minors' access, STAKE Act, ethnicity

In the late 1980s and early 1990s, children aged 12-17 years were successful at purchasing cigarettes $60-90 \%$ of the time, ${ }^{1-5}$ and purchased approximately 1 billion packs of cigarettes each year ${ }^{6}$ despite laws banning the sale of tobacco to minors. ${ }^{78}$ Clearly, more comprehensive policies were needed to reduce minors' access. Three such policies were implemented in 1994-96: the Synar Regulation, ${ }^{9}$ the Food and Drug Administration (FDA) regulation RIN 0910-AA48, ${ }^{10}$ and the California STAKE Act. ${ }^{11}$ The Synar and FDA policies require all states (as of January 1996) to enforce youth access laws, develop plans to decrease sales of tobacco to children to $\leqslant 20 \%$, and to provide documentation of that to the Substance Abuse and Mental Health Services Administration (SAMSHA). A state can lose up to $40 \%$ of its federal substance abuse prevention and treatment block grant funds for failure to comply with Synar. In California, compliance with Synar consisted of passing the Stop Tobacco Access to Kids Enforcement (STAKE) Act in 1994 (implemented in 1995). The STAKE Act requires the California Department of Health Services
Tobacco Control Section (TCS) to (among other things) implement an intense, statewide enforcement program to decrease tobacco sales to youth to $\leqslant 20 \%$ of their purchase attempts; conduct regular "sting operations" in stores throughout the state; and assure that California meets all of the requirements of Synar. ${ }^{11}$

Data on the effectiveness of Synar were provided by SAMSHA in $1998 .{ }^{12}$ SAMSHA compared studies of minors' access rates before the Synar legislation to studies of their rates post implementation of Synar (that is, results from the 1997 block grant applications). SAMSHA found prelegislation access rates of $60-90 \%$, and postimplementation access rates of $31-50 \%$ in most states, with $25 \%$ of states sampled reporting rates of $30 \%$ or less. ${ }^{12}$ Although SAMSHA's findings are encouraging, they are problematic because the studies compared by SAMSHA were conducted in different communities, stores, and types of stores, by investigators who utilised significantly different methodologies. ${ }^{12}$ Observed decreases in youth access to tobacco thereby may not be a function of the legislation but instead an artifact of using different stores, types of stores, and methodologies. To assess the effectiveness of Synar, minors' access to tobacco must be assessed in the same national set of stores, using a single methodology, preand post-Synar. No such study exists.

Likewise, the California Department of Health Services TCS annually collects statewide data on the effectiveness of the STAKE Act. These "youth purchase surveys" are conducted by the authors (EK) and indicate a steady decline in youth access to tobacco in California - that is, from 37\% in 1995 (when STAKE took effect), to $29.3 \%$ (1996), to $21.7 \%$ (1997), to $13.1 \%$ in $1998 .{ }^{13}$ Although these findings appear to suggest that the STAKE Act has been effective, there are two reasons that these data cannot be interpreted as such. The first is that TCS youth purchase surveys are never conducted in the same stores; rather, a new, random collection of stores is used each year as required by SAMSHA. This makes it difficult to know if the observed annual decreases are the result of the legislation and its enforcement, or are an artifact of using different stores. The second problem is that many of the stores included in TCS youth purchase surveys have participated in merchant education interventions conducted by TCS, making it difficult to know if the observed decreases are caused by the law and its enforcement or are the result of educat- 
Table 1 Percentage of packs of cigarettes sold to minors over time

\begin{tabular}{|c|c|c|c|c|c|}
\hline $\begin{array}{l}\text { Time 1 } \\
\text { August } \\
1994\end{array}$ & $\begin{array}{l}\text { Time } 2 \\
\text { August } \\
1995\end{array}$ & $\begin{array}{l}\text { Time } 3 \\
\text { August } 1996\end{array}$ & $\begin{array}{l}\text { Time } 4 \\
\text { March } \\
1998\end{array}$ & $\begin{array}{l}\text { Time } 5 \\
\text { fanuary } \\
1999\end{array}$ & $\begin{array}{l}\chi^{2} \text { Analyses of differences by } \\
\text { time period }\end{array}$ \\
\hline $41.2 \%$ & $32.3 \%$ & $34.7 \%$ & $12.7 \%$ & $15.2 \%$ & Time $1>2=3>4=5$ \\
\hline
\end{tabular}

ing merchants. Hence, the evidence provided by TCS (like that provided by SAMSHA) at best only tentatively suggests that the STAKE Act has reduced minors' access to tobacco in California. To assess the effectiveness of the STAKE Act, California minors' access to tobacco must be examined with a single methodology, in exactly the same stores, with those stores excluded from merchant education interventions, pre- and post-STAKE Act. We report that unique analysis.

\section{Method}

MINORS

Five groups of 16 year olds were recruited, one for each time period. The number in the group for each time period was: time period $1, \mathrm{n}=6$ (three girls, three boys); time periods 2 and 3, $\mathrm{n}=4$ (two girls, two boys); time periods 4 and $5, \mathrm{n}=12$ (six girls, six boys). All minors were matched for physical size and appearance and were the children of college faculty and students.

\section{STORES}

Seventy two small grocery/convenience stores were randomly selected in our 1993-95 study, with 24 stores in black, white, and Latino communities, as detailed elsewhere. ${ }^{7-8}$ These 72 stores were selected because they have been excluded from all merchant education interventions to reduce minors' access to tobacco conducted in San Bernardino County 1993 to 1999.

PROCEDURES

The procedures used in the initial data collection (1993-95) were used in each time period of this study, and are detailed elsewhere. ${ }^{78}$ These included selecting minors not at risk for smoking; obtaining informed consent from minors and their parents; providing adult escorts to assure minors' safety; training minors to standardise their purchase attempts, and role playing potential interactions with clerks to standardise minors' behaviour; obtaining immunity from prosecution for minors for making purchase attempts; and debriefing minors and their parents. Each year of the study had the approval of the institutional review boards of two institutions.

PURCHASE ATTEMPTS

As in the 1993-95 study, $^{78}$ all purchase attempts transpired from $3 \mathrm{pm}$ to $7 \mathrm{pm}$ on weekdays, and minors were paid for each purchase attempt irrespective of its success. The purchase attempts in each time period transpired over 2-3 months. In each time period, each minor visited each store once to make a purchase attempt. There were 432 purchase attempts in time period 1 ( 6 minors $\times 72$ stores), 288 purchase attempts in time periods 2 and 3 (4 minors $\times 72$ stores), and 828 purchase attempts in time periods 4 and 5 (12 minors $\times 69$ of 72 stores, because three stores went out of business), for a total of 2664 purchase attempts. Purchase attempts were scheduled so that stores were visited by only two to three minors from the study each week. Purchase attempts were one hour to three days apart. Each child entered the store, went to the counter and asked, "May I have a pack of Marlboros, please?". Minors were provided with funds for the purchase, and all tobacco was confiscated from them after a successful purchase attempt.

TIME PERIODS EXAMINED

Minors attempted to purchase cigarettes in the 72 stores in each of five time periods: (1) MayAugust 1994 (before implementation of STAKE); (2) August-September 1995 (immediately postimplementation); (3) May-August 1996 (one year post implementation); (4) February-April 1998; and (5) November 1998-January 1999 (both postimplementation). Purchase attempts were 7-18 months apart.

\section{Results}

Tables 1 and 2 present $\chi^{2}$ analyses. As shown in table 1, minors' access rate in 1994 (before implementation, time 1 ), was $41.2 \%$. This decreased significantly to $32.2 \%$ one year later (time 2, 1995) when the STAKE Act was implemented. Minors' access rate then

Table 2 Percentage of packs of cigarettes by neighbourhood over time

\begin{tabular}{|c|c|c|c|c|c|c|}
\hline Census tract & Time 1 Aug 1994 & Time 2 Aug 1995 & Time 3 Aug 1996 & Time 4 March 1998 & Time 5 fan 1999 & $\begin{array}{l}\text { Row analyses: within tracts } \\
\text { over time }\end{array}$ \\
\hline White & $39.3 \%$ & $22.9 \%$ & $35.4 \%$ & $11.5 \%$ & $15.1 \%$ & Time $1>2=3>4=5$ \\
\hline Black & $38.9 \%$ & $36.5 \%$ & $28.1 \%$ & $14.9 \%$ & $13.9 \%$ & Time $1=2=3>4=5$ \\
\hline Latino & $45.5 \%$ & $37.5 \%$ & $40.6 \%$ & $11.5 \%$ & $16.6 \%$ & Time $1=2=3>4=5$ \\
\hline $\begin{array}{l}\text { Column analyses: between } \\
\text { tracts ( } \mathrm{df}=2 \text { for each) }\end{array}$ & $\chi^{2}=1.6 \mathrm{~ns}$ & $\chi^{2}=5.81 \mathrm{~ns}$ & $\chi^{2}=3.34 \mathrm{~ns}$ & $\chi^{2}=1.96 \mathrm{~ns}$ & $\chi^{2}=0.79 \mathrm{~ns}$ & \\
\hline
\end{tabular}

Within tract over time effects:

White tracts: time $1 v 2 \chi_{\text {(df 1) }}^{2}=7.05, \mathrm{p}=0.008$; time $1 v 3 \chi_{\text {(df 1) }}^{2}=0.373, \mathrm{p}=0.54$; time $1 v 4 \div \chi_{\text {(df 1) }}^{2}=41.92, \mathrm{p}=0.0005$; time $1 v 5 \chi_{\text {(df 1) }}^{2}=29.69, \mathrm{p}=0.0005$; time $2 v 3 \chi_{2}^{2}$ (df 1) $=3.63, \mathrm{p}=0.06$; time $2 v 4 \chi_{\text {(df 1) }}^{2}=7.23, \mathrm{p}=0.007$; time 2 v $5 \chi_{\text {(df 1) }}^{2}=2.99, \mathrm{p}=0.08$; time $3 v 4 \chi_{\text {(df } 1)}^{2}=26.80, \mathrm{p}=0.0005$; time $3 v 5 \chi_{\text {(df 1) }}^{2}=17.52, \mathrm{p}=0.0005$; time 4 v $5 \chi_{\text {(df } 1)}^{2}=1.39, \mathrm{p}=0.24$.

Black tracts: time $1 v 2 \chi_{\text {(df 1) }}^{2}=0.15, \mathrm{p}=0.70$; time $1 v 3 \chi_{\text {(df 1) }}^{2}=2.95, \mathrm{p}=0.09 ;$ time $1 v 4 \chi_{\text {(df 1) }}^{2}=31.19, \mathrm{p}=0.0005 ;$ time $1 v 5 \chi_{\text {(df 1) }}^{2}=34.71, \mathrm{p}=0.0005$; time $2 v 3 \chi_{2}^{2}$ (df 1) $=1.53, \mathrm{p}=0.22$; time $2 v 4 \chi_{\left.\text {(df }_{21}\right)}^{2}=20.62, \mathrm{p}=0.0005 ;$ time $2 v 5 \chi_{(\text {df } 1)}^{2}=23.34, \mathrm{p}=0.0005$; time $3 v 4 \chi_{(\mathrm{df} 1)}^{2}=8.41$, $\mathrm{p}=0.004$; time $3 v 5 \chi_{(\mathrm{df} 1)}^{2}=10.13, \mathrm{p}=0.001$; time $4 v 5 \chi_{(\mathrm{df} 1)}=0.13, \mathrm{p}=0.72$.

Latino tracts: time $1 v 2 \chi^{2}$ (df $=1.49, \mathrm{p}=0.22$; time $1 v 3 \chi_{\text {(df } 1)}^{2}=0.55, \mathrm{p}=0.46$; time $1 v 4 \chi^{2}$ (df $=62.22, \mathrm{p}=0.0005 ;$ time $1 v 5 \chi^{2}$ (df $=41.48, \mathrm{p}=0.0005$;

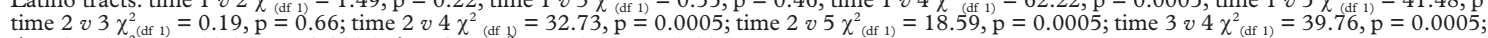

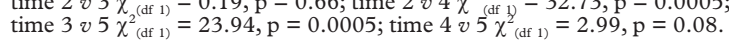
ns, not significant. 
Table 3 Stepwise and hierarchical logistic regressions predicting sold versus not sold from time period and neighbourhood

\begin{tabular}{|c|c|c|c|c|}
\hline $\begin{array}{l}\text { Stepwise regression } \\
\text { Variable selected/step }\end{array}$ & Coefficient & Coefficient/SE & Odds ratio & $95 \% C I$ \\
\hline Step 1: time period & \multicolumn{4}{|c|}{ Reference group: time 5 (January 1999) } \\
\hline Time 1: August, 1994 & 1.365 & 9.93 & 3.92 & $2.99,5.13$ \\
\hline Time 2: August, 1995 & 0.98 & 6.17 & 2.67 & $1.95,3.64$ \\
\hline Time 3: August 1996 & 1.089 & 6.93 & 2.97 & $2.18,4.04$ \\
\hline Time 4: March 1998 & -0.206 & 1.45 & 0.814 & $0.616,1.076$ \\
\hline \multicolumn{5}{|l|}{ Hierarchical regression } \\
\hline Step 1: time period & \multicolumn{4}{|c|}{ Reference group: time 5 (January 1999) } \\
\hline Time 1: August 1994 & 1.372 & 9.97 & 3.94 & $3.01,5.17$ \\
\hline Time 2: August 1995 & 0.986 & 6.20 & 2.68 & $1.96,3.66$ \\
\hline Time 3: August 1996 & 1.096 & 6.97 & 2.99 & $2.19,4.07$ \\
\hline Time 4: March 1998 & -0.206 & -1.45 & 0.814 & $0.616,1.076$ \\
\hline Step 2: neighbourhood & \multicolumn{4}{|c|}{ Reference group: white } \\
\hline Black & 0.086 & 0.716 & 1.09 & $0.86,1.38$ \\
\hline Latino & 0.222 & 1.87 & 1.25 & $0.99,1.58$ \\
\hline
\end{tabular}

remained stable (time 3, 1996), then decreased significantly during the next $12-18$ months (time 4,1998 ) to $12.7 \%$, and remained low thereafter (time 5, 1999, 15.2\%). This decrease occurred in all ethnic communities (table 2), but appears (in the $\chi^{2}$ analyses at least) to have occurred more quickly (that is, at time 2) in white than in minority communities (row analyses table 2); access in all communities, however, was the same (column analyses, table 2) irrespective of time period.

To clarify these findings, stepwise and hierarchical logistic regressions were conducted, predicting sale versus no sale from time period and census tract (table 3 ). In the stepwise analysis, time period was the only predictor selected; the same 72 stores were 3-4 times more likely to sell cigarettes to minors before than after implementation of the STAKE Act. Results for the hierarchical regression were the same, with no significant effect for ethnic neighbourhood.

\section{Discussion}

Minors attempted to purchase cigarettes in precisely the same 72 stores, in exactly the same manner, in five time periods, each time period separated by about a year. One of the time periods was before implementation of the STAKE Act and the remainder were after implementation. Results revealed that minors' access decreased significantly after implementation of the STAKE Act and then continued to decrease over time. These decreases cannot be attributed to interventions with merchants because this set of stores has been excluded from those. Likewise, the decreases cannot be attributed to using different stores each year, because the same stores were used; similarly, the decreases cannot be attributed to the status characteristics of the minors because all minors in all time periods were 16 years old, were half girls and half boys, and were matched for size and appearance. Hence, it is reasonable to conclude that these decreases in minors' access are the result of the California STAKE Act and its enforcement. These findings suggest that passing and enforcing local youth access policies can reduce youth access to tobacco.

This study was supported by funds provided by the University of California Tobacco-Related Disease Research Program grant 4RT-0348 and 6RT-0081, and by the California Department of Health Services Tobacco Control Section Grants 90-11528, 94-20962, and 96-26617 (STAKE Act).

1 Centers for Disease Control. Cigarettes sales to minorsColorado, 1989. MMWR Morb Mortal Wkly Rep.1990; 39:794-5, 801

2 DiFranza JR, Brown LJ. The Tobacco Institute's "It's the Law" campaign: has it halted illegal sales of tobacco to children? Am F Public Health 1992;82:1271-3.

3 Forster JL, Hourigan M, McGovern P. Availability of cigarettes to underage youth in three communities. Prev Med 1992;21:320-8

4 Radecki TE, Zdunich CD. Tobacco sales to minors in 97 US and Canadian communities. Tobacco Control 1993; 2:300-5.

5 Kirn TF. Laws ban minors' tobacco purchases, but enforcement is another issue. $\mathscr{f} A M A$ 1987;257:3323-4.

6 DiFranza JR, Tye JB. Who profits from tobacco sales to children? IAMA 1990;263:2784-7.

7 Klonoff EA, Landrine H, Alcaraz R. An experimental analysis of sociocultural variables in sales of cigarettes to minors. Am F Public Health 1997;87:823-6.

8 Landrine $\mathrm{H}$, Klonoff EA, Alcaraz R. Asking age and ID may reduce minors' access to tobacco. Prev Med 1996;25:3016.

9 Substance Abuse and Mental Health Service Administration. Tobacco regulation for substance abuse prevention and treatment block grants: final rule. Federal Register 1996;16:1492-500

10 Food and Drug Administration. Regulations restricting the sale and distribution of cigarettes and smokeless tobacco to protect children and adolescents: final rule. Federal Register 1996;61:44369-5318.

11 Stop Tobacco Access to Kids Enforcement (STAKE) Act. Business and Professions Code 22950-22960.

12 Substance Abuse and Mental Health Services Administration (SAMSHA). Synar Regulation Implementation: FY 97 State Compliance: Report to Congress. Depar
Health and Human Services, February, 1998.

13 California Department of Health Services, Office of Public Affairs. Illegal sales of tobacco to kids in California continue to plummet. California Department of Health Services, Office of Public Affairs, Press Release No 85-98, September 2, 1998 . 